\title{
قياس اتجاهات طلبة الجامعة نحو الانتقام
}

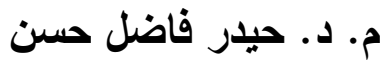 \\ جامعة بغداد / مركز البحوث التريوية وإلنفسية \\ دكتوراه في علم النفس العام
}

\section{Haider_971@perc.uobaghdad.edu.iq}

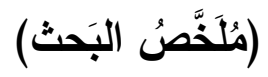

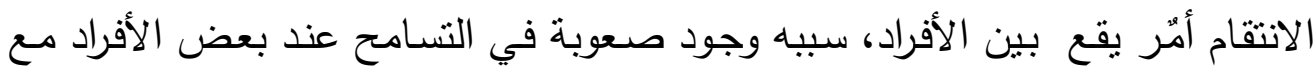

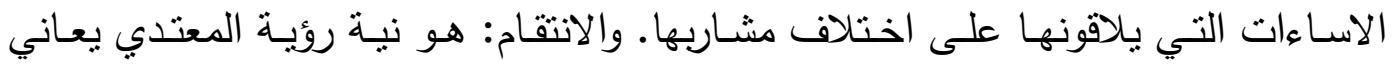
ويهدف هذا البحث الى بناء مقياس لاتجاهـات طلبة الجامعة نحو الانتقام وقياس هذه الاتجاهات، والتعرف على الفروق في اتجاهات طلبة الجامعة نحو الانتقام على وفق متغير الجنس ومتغير التخصص الدراسي. تكونت عينة البحث من ( . . (1) طالب وطالبة من البن التخصصين إلانساني والعلمي وقد قام الباحث بيناء مقياس اتجاهات طلبة الجامعة نحو

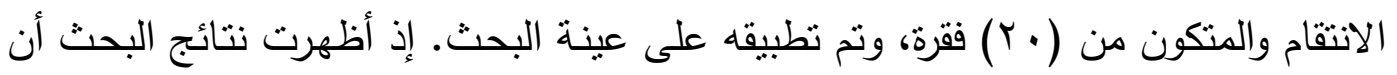

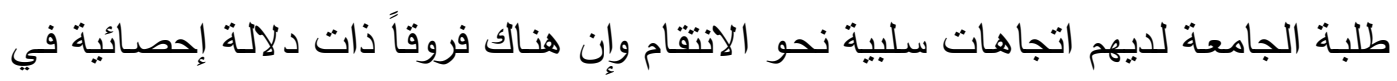

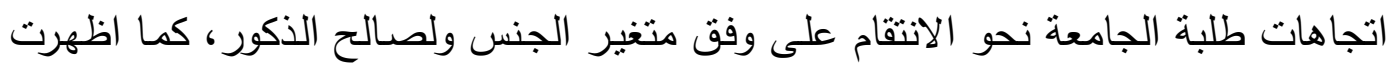
النتائج عدم وجود فروق ذات دلالة احصائية في اتجاهات طلبة الجامعة نحو الانتقام الجام وفقاً

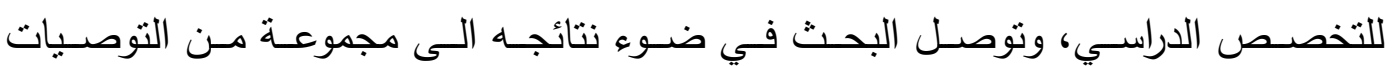
والمقترحات. الكلمات المفتاحية: اتجاهات. طلبة الجامعة. الانتقام.

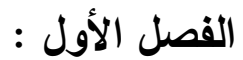
أهمية البحث والحاجة اليه :

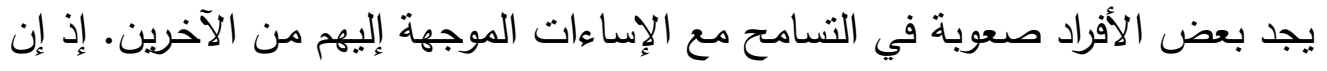
المشاعر السلبية التي يشعر بها الفرد الذي وقعت عليه الاساءة، هي مشاعر طبيعية اتجاه الاهناه

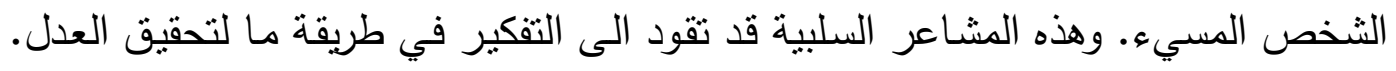

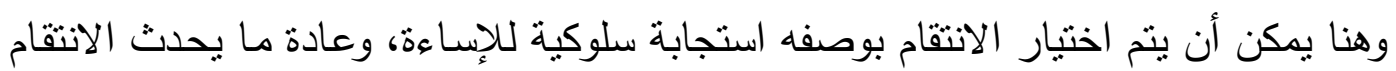

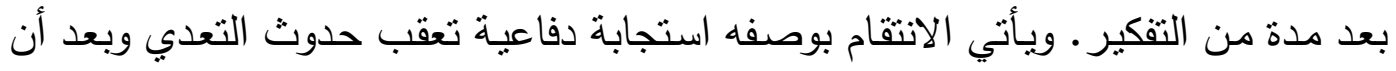

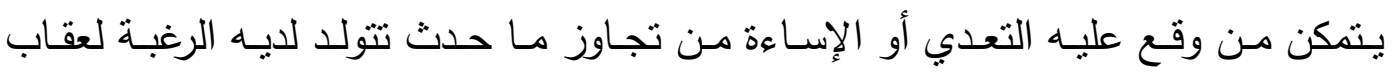

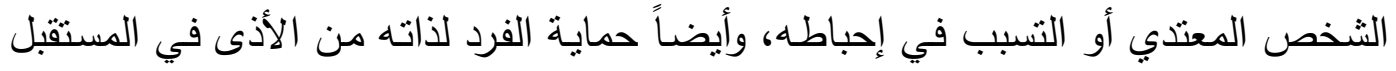


وبهذا المعنى فإن الغاية من الانتقام هي محاولة الرجوع الى حالة الاستقرار التي كانت قبل حدوث الإساءة.(Al-Baqmi, 2017, 192) والانتقام هو ظاهرة تقع بين الأفراد، والمدى الذي يندفع فيه الناس للانتقام يكون بدرجة

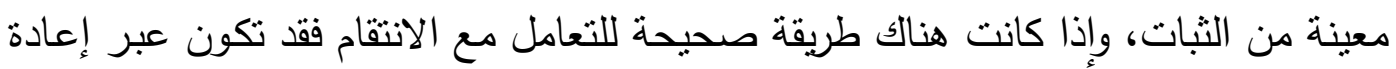

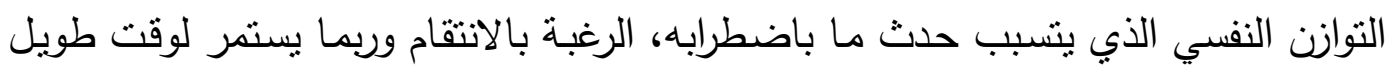
وتكون رغبة مضطربة، ويعزى هذا الى مشكلات مبكرة في النمو والى سمات شخصية

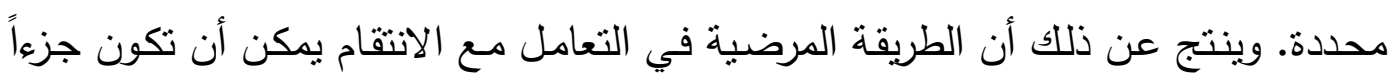

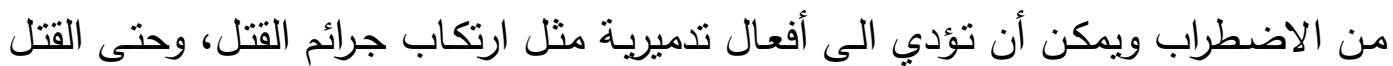

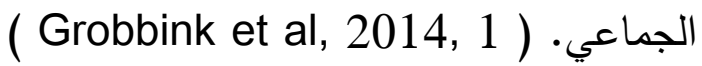
ومن أجل فهم الرضا الناتج عن مشاعر الانتقام يمكن الأخذ بنظر الاعتبار الأهداف

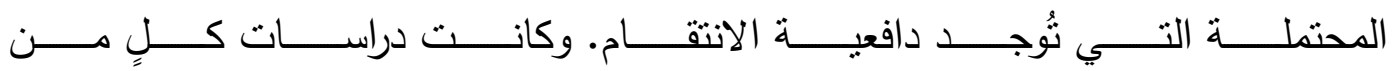
قد حددت عَدة (Frijda, 1994, McCullough et al, 2001; Vidmar, 2000) أهدافاً منها، أولاً : يراد من الانتقام إعادة التوازن في الدكاسب والخسائر التي حدثت بسبب

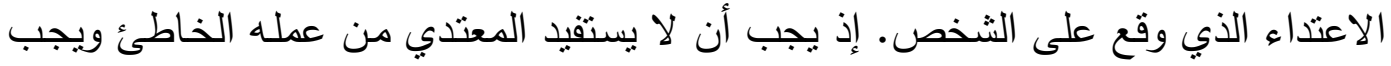

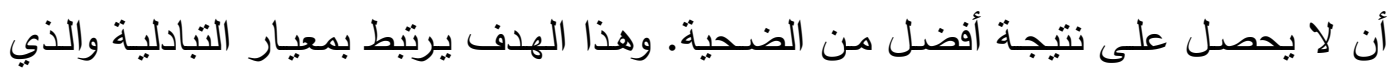

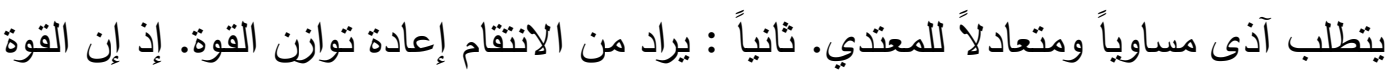

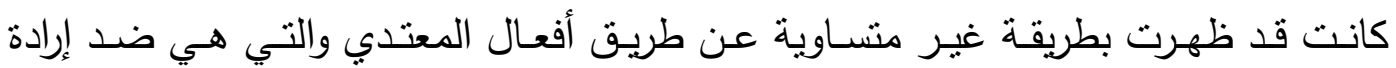

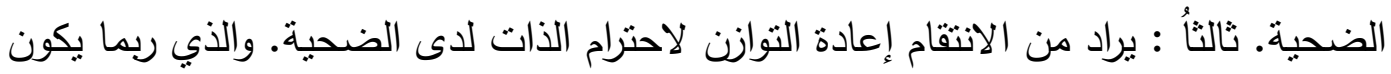

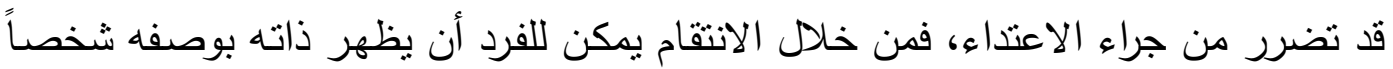

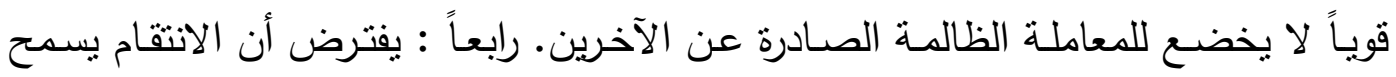

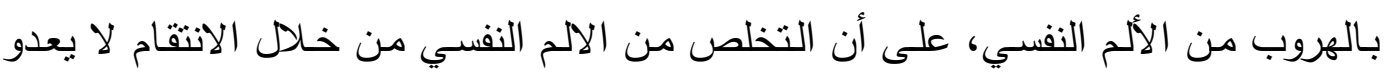
كونه موقتاً، في حين أن الالم المحدد والذي تسبب فيه الاعنداء يستمر بشكل عام. (Orth, 2004, 3 )

وانطلاقاً مما تقدم، فإن البحث الحالي يحاول التعرف على اتجاهات طلبة الجامعة نحو

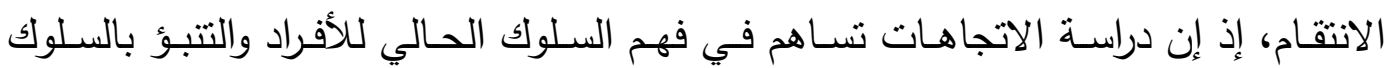

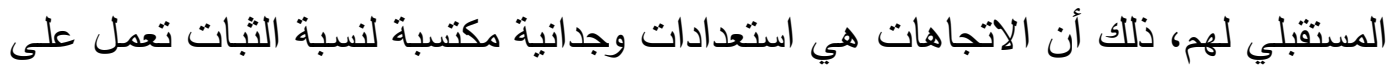

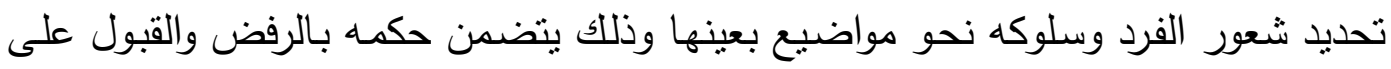
تلك المواضيع ويتضمن اشباءٍ أو اثخاصاً أو افكاراً. (Muhammad, 2004, 125) وإذاذ كان مفهوم الاتجاه واسعاً، فإن من بين ما يدل عليه هذا الدفهوم، توجه الفكر والاستعدادات

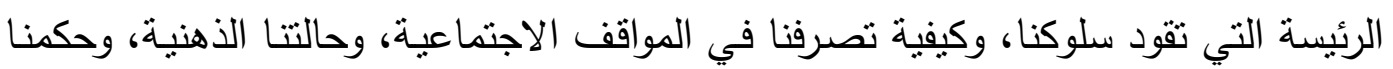


على القيم، فضـلاً عن اتجاهاتتا ترتبط بالمواضيع التي تتكون نحوها من جهة وترتبط بنا نحن وبدافعيتتا الذاتية من جهة آخرى، والإتجاهات هي مجموعة من الاستجابات الثخصية على موضوعات محددة، يدركها الفرد على انها حالات وجدانية، انفعالات أو قيم، تشكل جزءاً لا يتجزأ من شخصيته.(Selami, 2001, 56) يحمل الأفراد اتجاهات نحو كل شيء يقابلونه وتؤدي الخبرة الاجتماعية دوراً في تثكيل الاتجاهات، أن افكار الأفراد حول الموضوعات المتعلقة بالاتجاه تبنى على كلٍّ من المعرفة والخبرة، ولذا فإن الاتجاهات تكتسب من خـلا الملاحظة والاشتراط الاستجابي والاشتراط

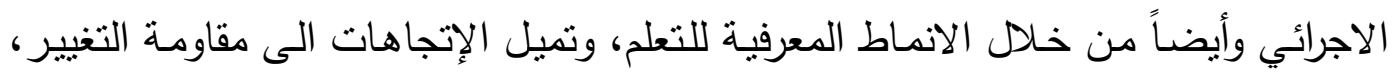
فالاتجاهات المتأصلة والراسخة تشكل خبرات الافراد تجاه الاثياء المتعلقة بها، ومن ثم تؤثئر

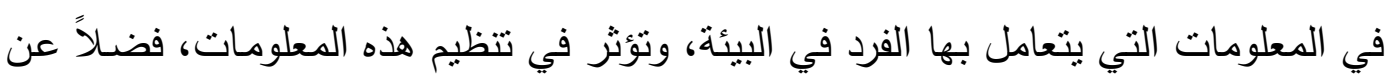

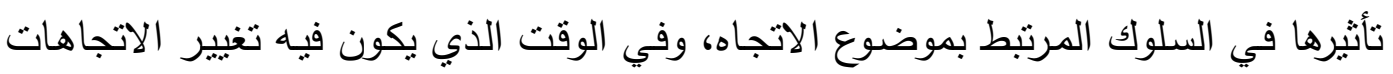

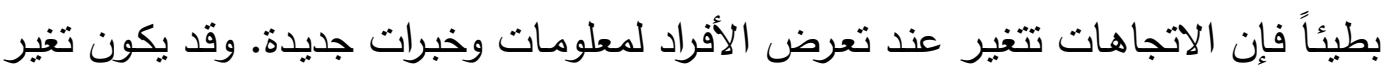

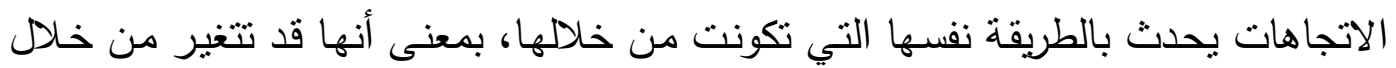
الانماط المعرفية للتعلم والملاحظة والاثتراط الاستجابي والاشتراط الاجرائي.

(Davidoff, 1980, 775-777)

ومن كلٍّ ما تقّدم تتضـح أهمية البحث الحالي لكونه يمثل محاولة لفهم اتجاهات طلبة

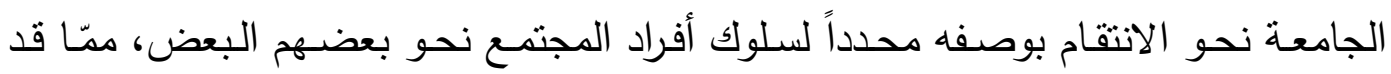

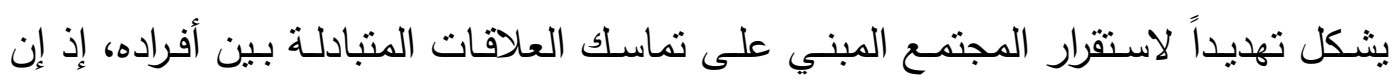

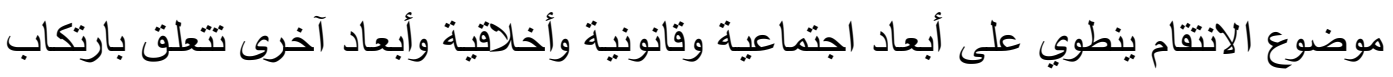

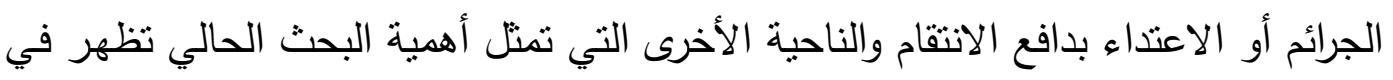

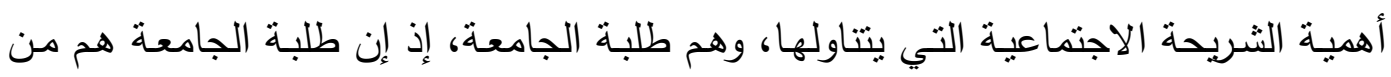

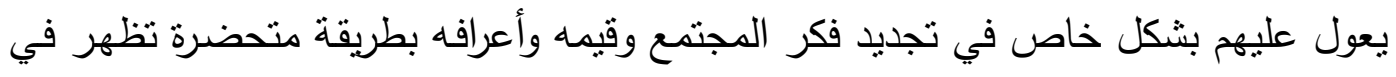

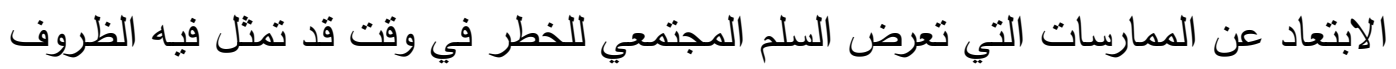
الاجتماعية التي مرّ ويمرّ بها العراق بيئة خصبة لأعمال العنف، والعنف المضاد العاد المتمثل فئل

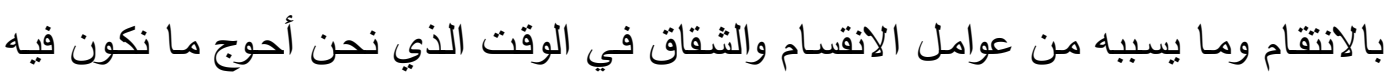
للحمة الاجتماعية ولسيادة القانون لكي نستطيع المحافظة على سيلم المجتمع وأمنه ورفاهيته. أهداف البحث : يهدف البحث الحالي الى :

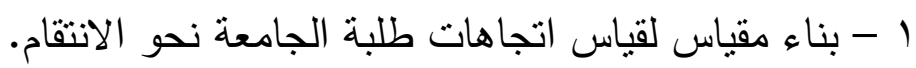

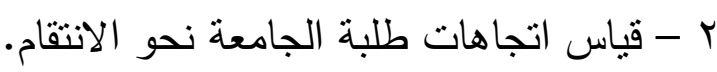
r - التعرف على الفروق في اتجاهات طلبة الجامعة نحو الانتقام على وفق متغير الجنس. 
ـ - التعرف على الفروق في اتجاهـات طلبـة الجامعـة نحو الانتقام على وفق متغير

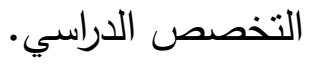
حدود البحث :

يتحدد البحث الحالي بطلبة جامعتي بغداد والمستتصرية، وبالدراسات الأولية وللمراحل الدراسية كافة. ومن كلا الجنسين (ذكور - أناث). تحديد المصطلحات :

سينت في هذا القسم تحديد مصطلحي (الاتجاهات) و و(الانتقام) وكما يأني:

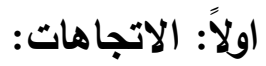

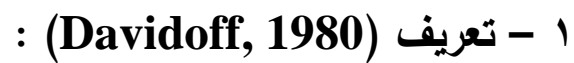

مفاهيم متعلقة وتقويمية ترتبط بأفكارنا ومشاعرنا وسلوكنا.(Davidoff, 1980, 775) r Foster, 1986 ) ( تعريف

شعور محدد حول شيء ما. يتضمن نزعة للسلوك بطريقة معينة في المواقف التي يكون

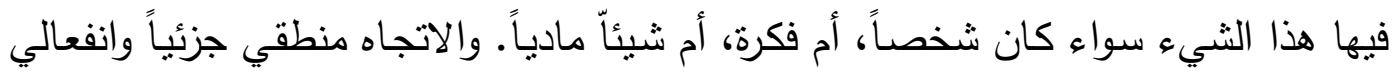

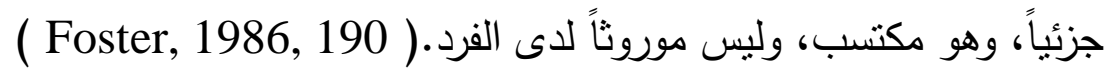

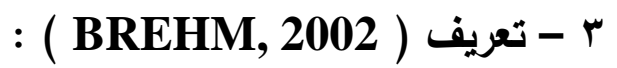

تقييم إيجابي، أو سلبي، أو مختلط لثـيء مـا، يعبر عنه بمستوى معيّن من الثندة.

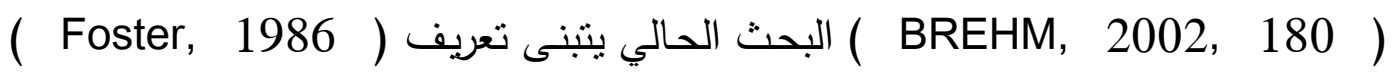
للاتجاهات لكون أن هذا التعريف ينسجم مع الإطار النظري للبحث الحالي ومع اجراءاته. التعريف الإجرائي للاتجاهات:

هي الدرجـة الكلية التي يحصل عليها المستجيب على الإداة المستخدمة في البحث الحالي لقياس اتجاهات طلبة الجامعة نحو الانتقام.

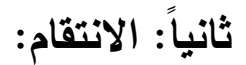

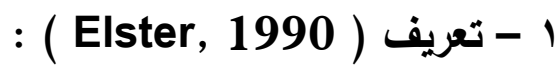

محاولة تتضمن مخاطرة أو كلفة على الفرد، تهدف لغرض معاناة على أولئك الذين

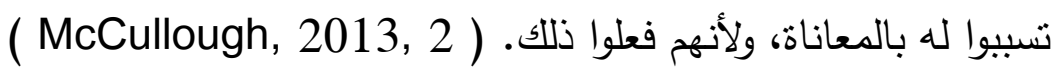

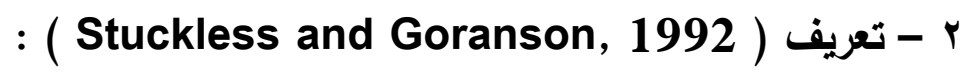
إما فرض عقاب مؤذٍ أو رد السلوك الى شخص رداً على الأذى أو الإهانة الدركة. (Al-Baqmi, 2017, 194)

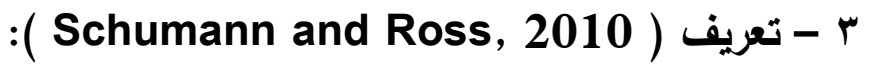
نية رؤية المعتدي، يعاني. (McCullough, 2013, 2 ) 
البحث الحالي ينبنى تعريف ( Schumann and Rossm 2010 ) للانتقام، إذ إن هذا التعريف ينسجم مع الإطار النظري للبحث الحالي ومع إجراءات البحث. التعريف الاجرائي للانتقام : هذبع الإنسام

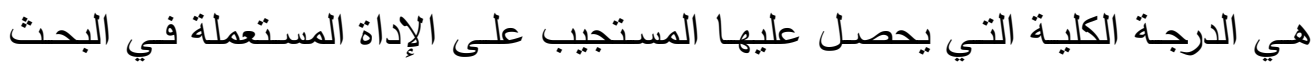
الحالي لقياس اتجاهات طلبة الجامعة نحو الانتقام.

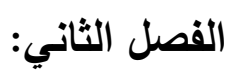
الإطار النظري والدراسات السابقة: يمكن أن ينظـر للاتجاهـات على أنها أنظمــة مـن الاستجابات الانفعاليـة والتقييميـة

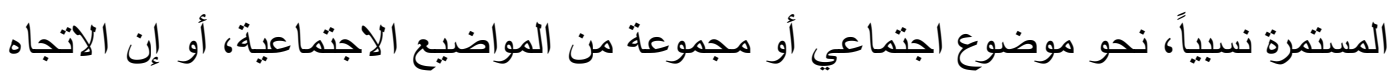

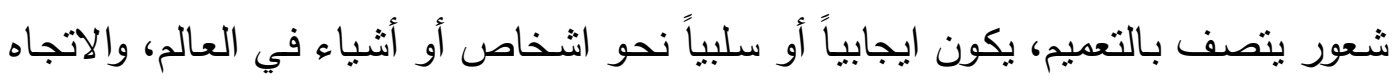

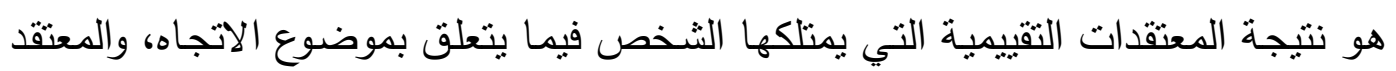

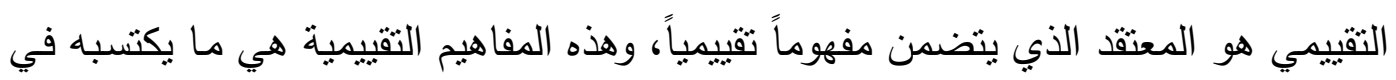

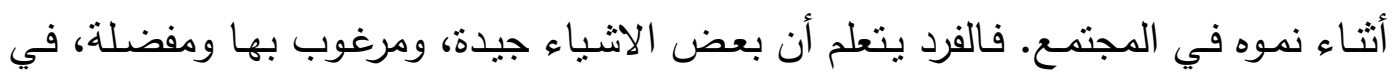

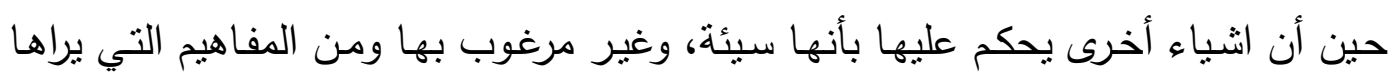

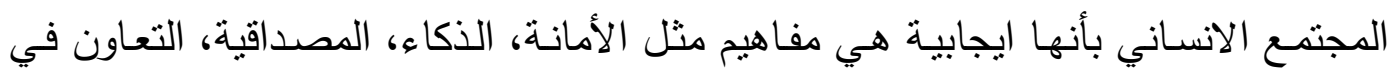

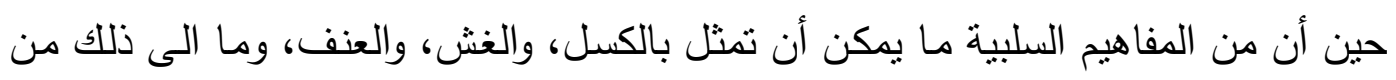

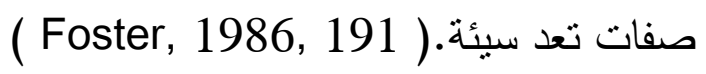

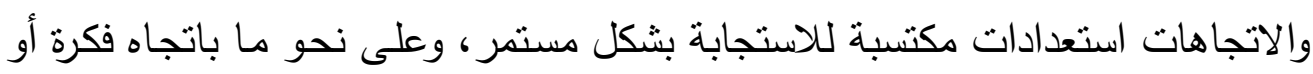
شيء. وقد تكون الاتجاهات اجتماعية عندما يتعلق بموضوع ينطوي على مدى اجتماعي. وأيضاً قد تكون اتجاهات شخصية عندما تتعلق بالقضايا الثخصية للفرد مثل تفضيلاته

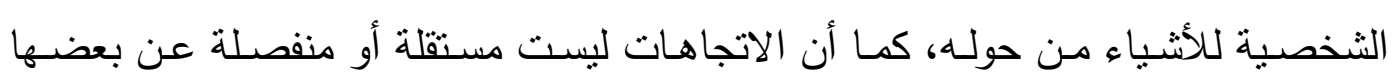

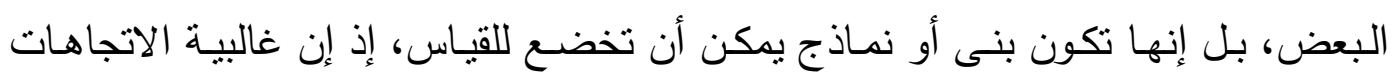

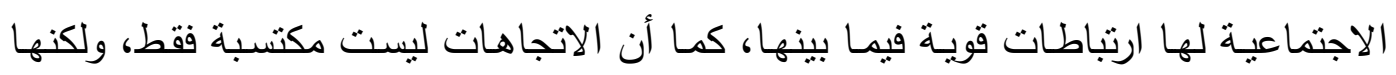

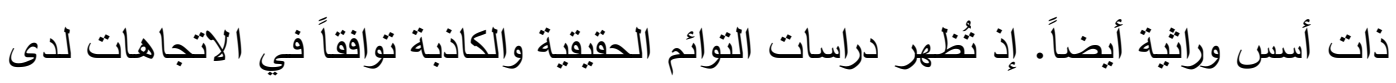

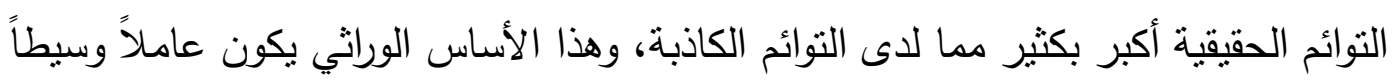

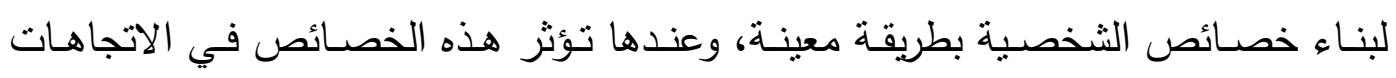

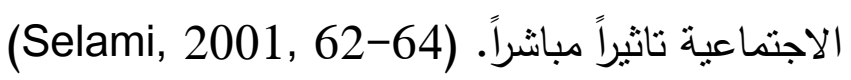
واذا كان للوراثة دور كبير في تكوين الاتجاهات من خلال الفروق الفردية الموروثة مثل بعض الصفات الجسمية والذكاء، فإن العامل الأهم في تكوين الاتجاهات يبقى عامل الاهن البيئة

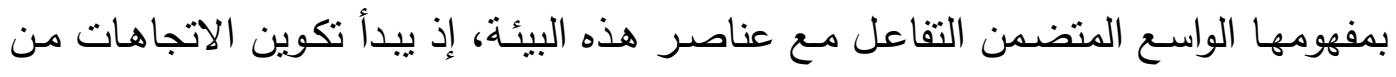


الأسرة بواسطة عملية التتشئة الاجتماعية المبنية على قيم ومعايير تلك الأسرة، فالاتجاهات

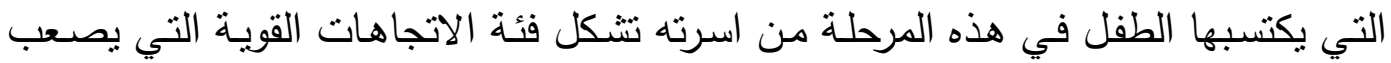
تغييرها. ومن ثم يأني دور المدرسة في تكوين الاتجاهات لدى الفرد والذي يمثل دوراً قوياً

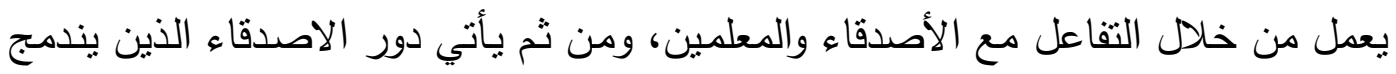

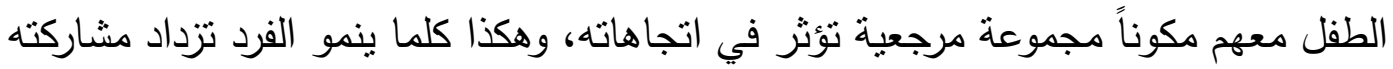

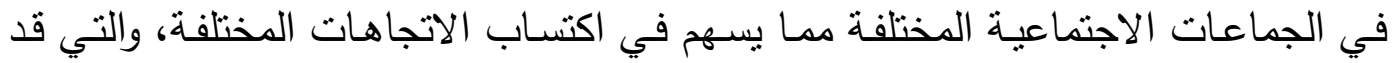
تكون مغايره لاتجاهاته الأولى التي اكتسبها من أسرته. (Muhammad, 2004, 127 - 128)

وفي إطار الاتجاهات التي يحملها الأفراد نحو عدد لا يحصى من الموضوعات، تأتي

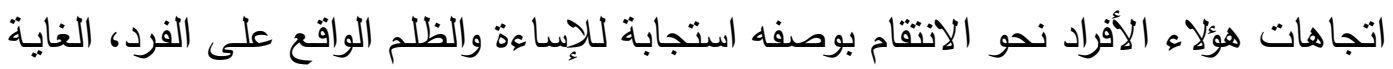

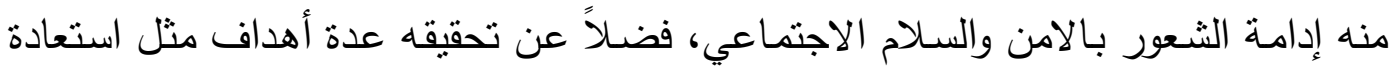

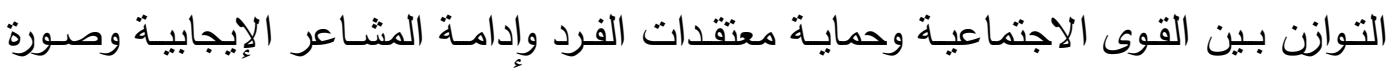
الذات، من ناحية، ومن ناحية أخرى فإن الانتقام له عواقب سلبية قد تقع على الته المنتقم نفسه

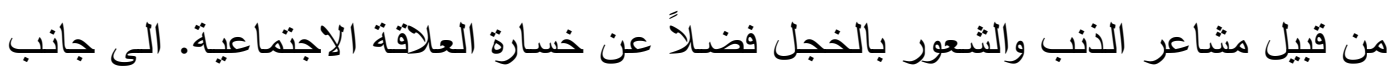
كل ذلك فإن الانتقام لا يمنح النتيجة التي يرغب بها المنتقم. (Al-Baqmi, 2017, 192) ومن الأطر النظريـة التي حاولت تفسير الانتقام، هي نظريـة الديناميكيات المعرفيـة

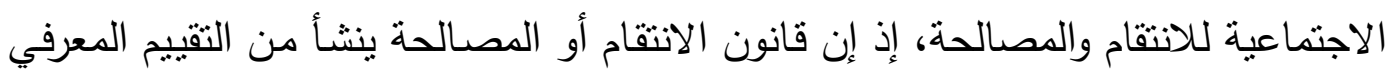

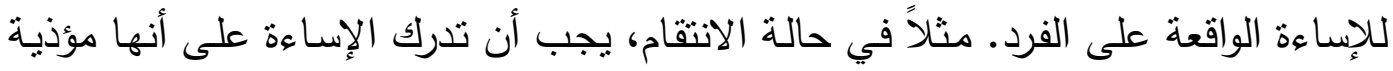

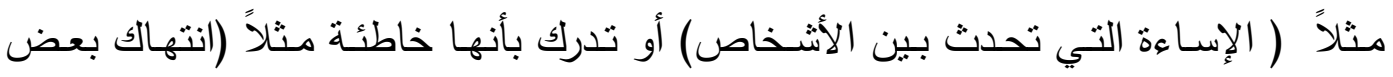

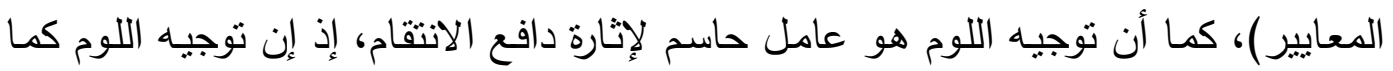

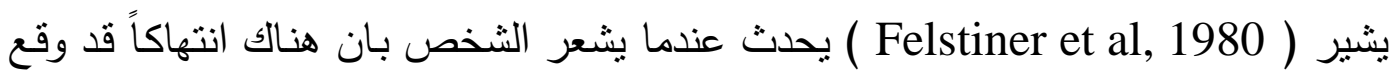
عليه ويعتقد بأن شيئًا يجب أن يتم عمله للاستجابة لهذا الانتهاك، إذا عُدَّ المعتدي مسؤولاًا

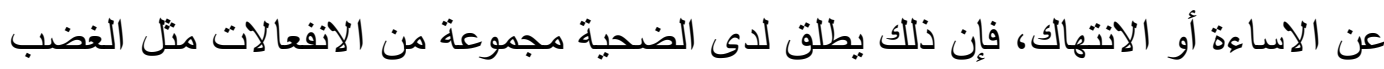

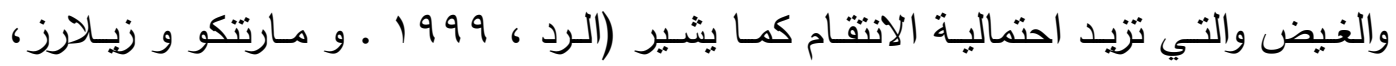
(Aquino et al, 2001, 53 ).(1991 في هذا الإطار جاءت دراسة (Aquino et al, 2001 ) تهدف الى معرفة العلاقة

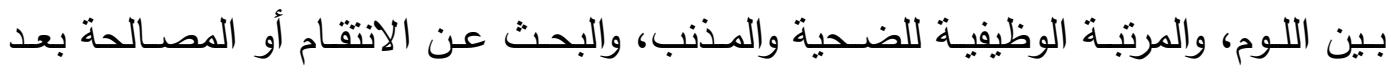
الإساءة الثخصية، وتكونت عينة الدراسة من ( (1) () موظفاً حكومياً. أظهرت نتائج البحث

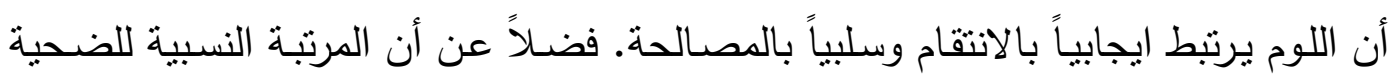

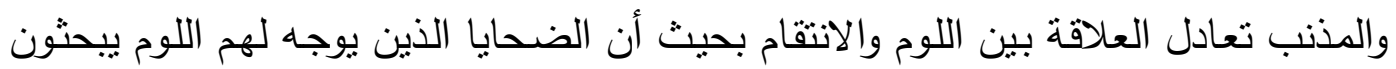


عن الإنتقام أكثر عندما تكون مرتبة المذنب ادنى من مرتبتهم، ومرتبة المذنب في التسلسل

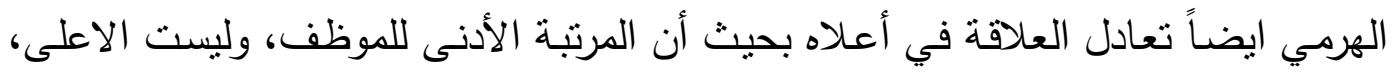
والذي يوجه له اللوم، هو من يبحث عن الانتقام اكثر . ( Aquino, 2001, 52 ) وقامت دراسة ( Aquino et al, 2006 ) بالتعرف عنى عنى العلاقة بين المتغيرات في داخل عمل المنظمات وبين الاستجابات المختلفة للضحايا عند ادراك الاعتداء، وذلك من

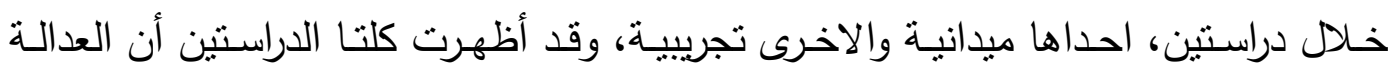
الاجرائية تعادل أثر المتغيرات المنظمية الخاصة بانتقام الضحية، وتسامحها، وتصالحها،

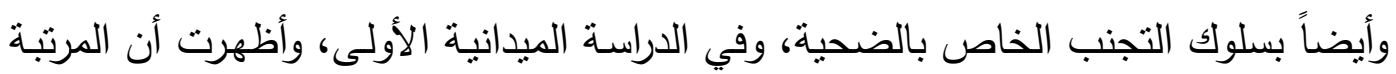

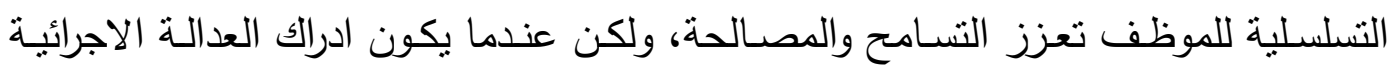

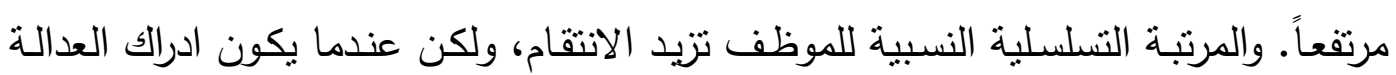
الإجرائية منخفضاً. وفي الدراسة الثانية، وهي دراسة تجريبية، ظهر أن الضحايا كانوا أقل

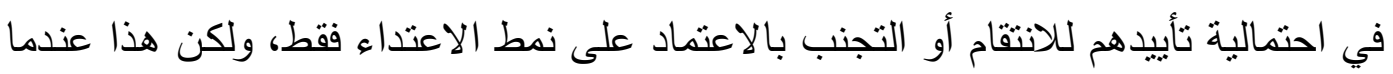

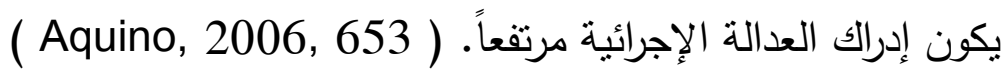

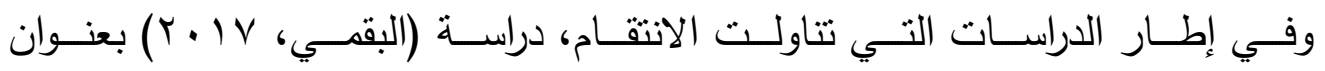

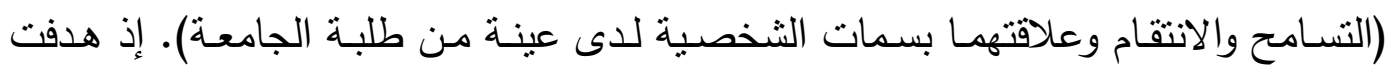

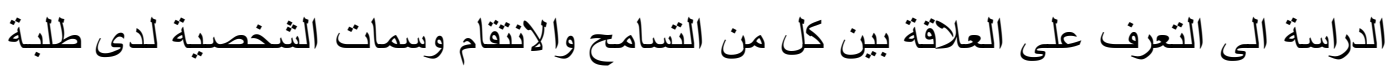
الجامعة، كذلك الكثف عن الفروق في التسامح والانتقام بين الذكور والاناث. وتكونت على عينة

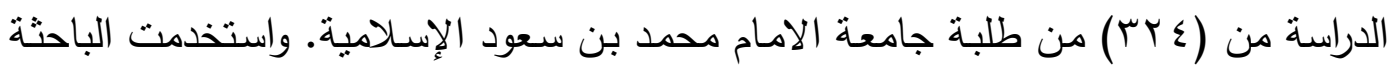

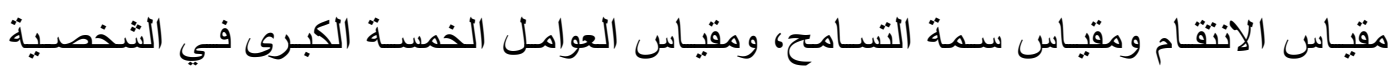

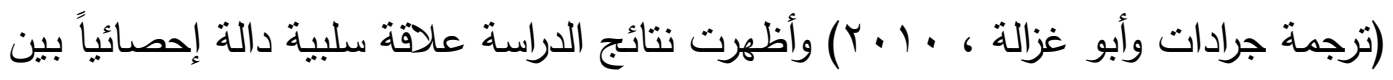

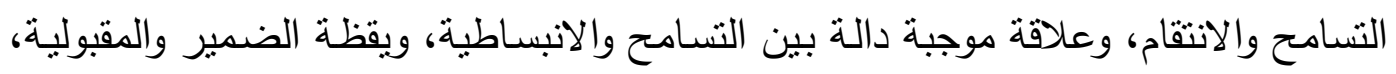

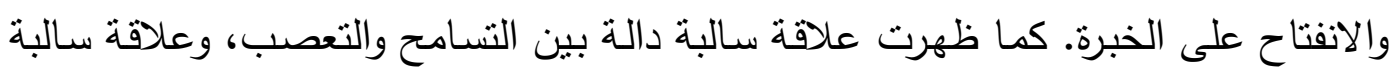

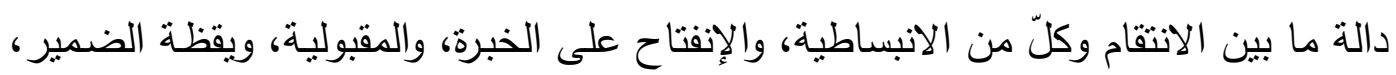

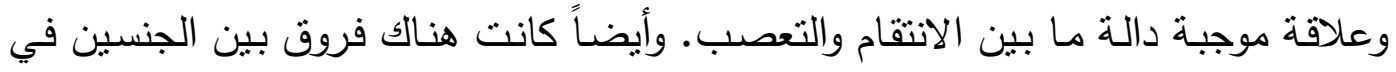

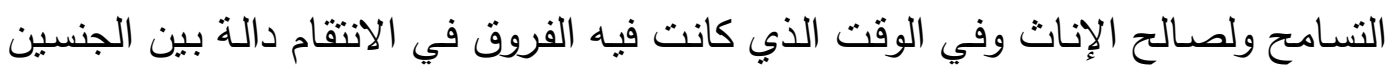
ولصالح الذكور • (Baqami, 2017, 190) الفصل الثالث: اجراءات البحث: اولاً : مجتمع البحث: يشكل مجتمع البحث الحالي طلبة كليات جامعة بغداد للسنة الدراسية

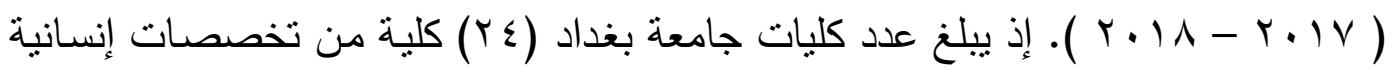


وعلميـة، وهذه الكليـات موزعـة الى (r ( ) كليـة ذات تخصص علمي و (r ( ) كليـة ذات تخصص إنساني. ثانياً : عينة البحث : أناني

تكونت عينة البحث من ( . . () طالب وطالبـة اختيروا بطريقة عشوائية من كليـات العلوم والصيدلة للتخصص العلمي، وكليات اللغات ولإعلام للتخصص الإنساني. وكان أفراد العينة موزعين بحسب الجنس والتخصص الدراسي بواقع (Y0) طالب وطالبة لكل كلية.

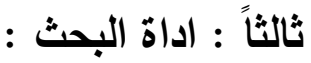
لغرض تحقيق أهداف البحث الحالي، قام الباحث بيناء مقياس يتكونّ من (•r) فقرة،

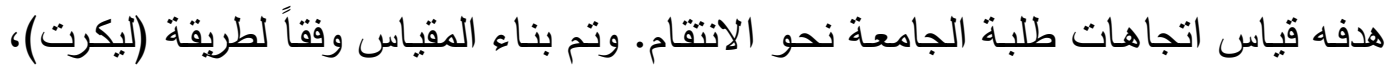

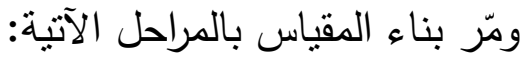
ا 1 - جمع فقرات المقياس:

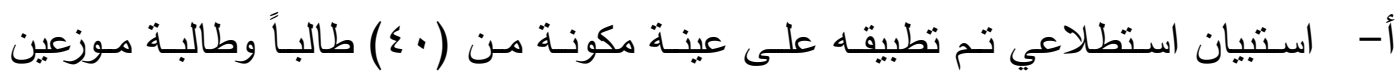

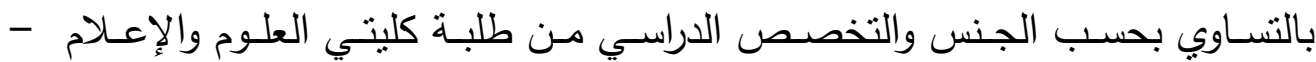

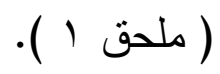

ب- الأدبيات السابقة التي نتاولت متغير الانتقام.

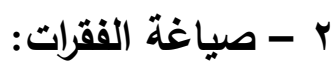

قام الباحث بصباغة (·r) فقرة، نوزعت الفقرات الى فقرات إيجابيـة تعكس اتجاهـاً إيجابياً نحو الانتقام، وفقرات سلبية تعكس اتجاهاً سلبياً نحوه.

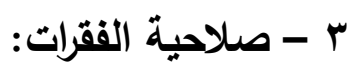

عرضـت الفقرات التـي تم جمعهـا وصـياغتها على مجموعـة مـن الخبـراء* لمعرفـة

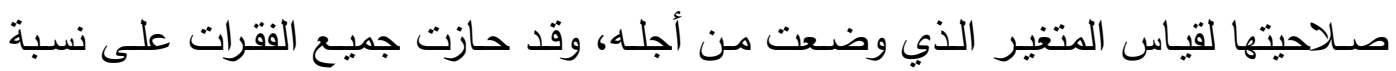
الاتفاق المطلوبة بين الخبراء هي (•A ٪) فأكثر لغرض ابقائها في المقياس.

كلية الآداب / الجامعة المستنصرية

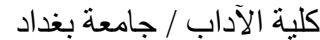

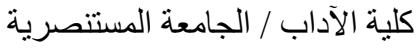

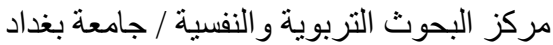

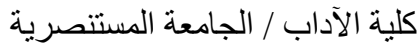

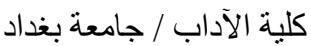
كلية الآداب / جامعة / جامعة بغداد مركز البحوث التربوية و النفسية / جامعة بغداد

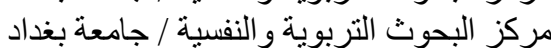
مركز البحوث التربوية والنفسية / جامعة بغداد
قسم علم النفس

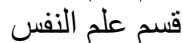
قسم علم النفس النفر قسم البحوث النفسية قسم علم النفس النف قسم علم النفس عل قلف قسم علم النفس النفس قسم البحوث النفسية قسم البحوث النفسية قسم البحوث التربوية

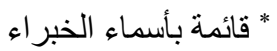

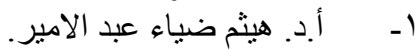
r

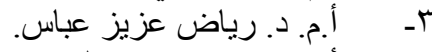
ع - أم. د. سفيان صائب المعاضيدي.

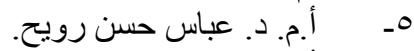

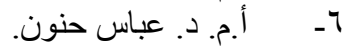

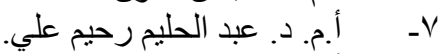

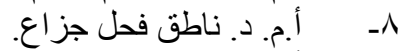

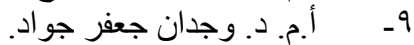
• 
لغرض التعرف على القوة التميزية لكل فقرة من فقرات المقياس قام الباحث باستعمال طريقة المجموعتين المتطرفتين. إذ تم ترتيب استمارات المقياس البالغ عددها ( . ( ) استمارة

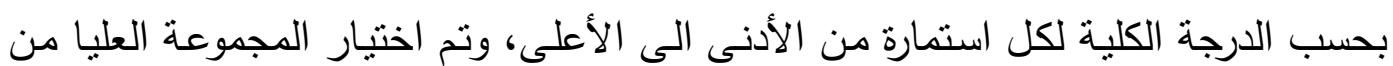

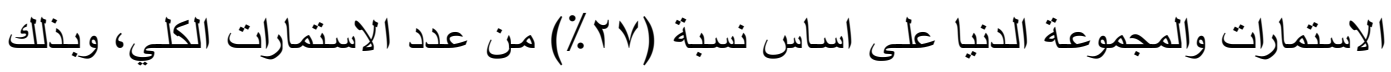
حصل الباحث على مجموعة عليا تمثل الاتجاه الايجابي نحو الانتقام ومجموعة دنيا تمثل الاتجاه السلبي نحو الانتقام. وبعد ذلك تم استعمال الاختبار التائي لعينتين مستقلتين لكل

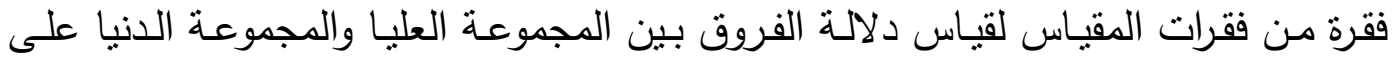
الفقرة، وظهر أن كلَّ الفقرات كانت تتمتع بالقوة التمييزية المطلوبـة لإبقائها في الاختبار .

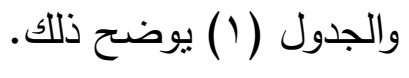

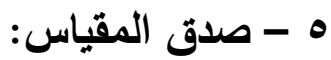
تم اعتماد الصدق الظاهري للقياس من خلال عرضه على مجموعة الخبراء الذين أبدوا

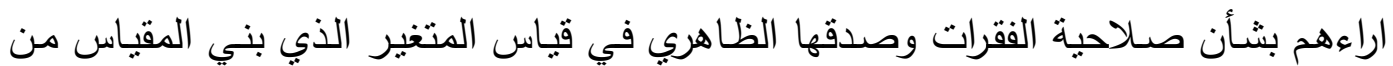

الجدول (1) الاختبار التائي لفقرات المقياس للمجموعتين العليا والدنيا

\begin{tabular}{|c|c|c|c|c|c|c|c|}
\hline النتيجة & مستوى الدلالة & القائية & $ت$ & النتيجة & مستوى الدلاكة & التائية & ت \\
\hline دالة & $\ldots 0$ & r. . & 11 & دالة & $\ldots 0$ & r.r. & 1 \\
\hline دالة & $\ldots 0$ & 1.99 & Ir & دالة & $\ldots 0$ & r. $\leqslant \theta$ & $r$ \\
\hline دالة & $\ldots 0$ & o.r.r. & 14 & دالة & $\ldots 0$ & r.l & $r$ \\
\hline دالة & $\ldots . . .$. & \&.Y. & $1 \varepsilon$ & دالة & $\ldots 0$ & 1.91 & $\varepsilon$ \\
\hline دالة & $\ldots 0$ & $1.9 \mathrm{~V}$ & 10 & دالة & $\ldots 0$ & T.Yo & 0 \\
\hline دالة & $\ldots 0$ & r.r. & 17 & دالة & $\ldots 0$ & r.Yr & 7 \\
\hline دالة & $\ldots 0$ & r.00 & IV & دالة & $\ldots 0$ & r.Y. & $\mathrm{v}$ \\
\hline دالة & $\ldots 0$ & \&.1. & 11 & دالة & $\ldots 0$ & \&.1. & $\wedge$ \\
\hline دالة & $\ldots 0$ & r.YA & 19 & دالة & $\ldots 0$ & r.o. & 9 \\
\hline دالة & $\ldots 0$ & r.7. & $r$. & دالة & $\ldots 0$ & r.A. & 1. \\
\hline
\end{tabular}

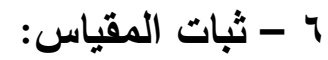

لغرض التعرف على ثبات المقياس المستخدم في البحث الحالي، استخدم الباحث طريقة

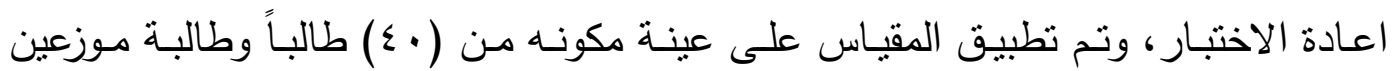


بحسب الجنس والتخصص الدراسي على كليتي العلوم والإعلام، ثم اعيد تطبيق المقياس

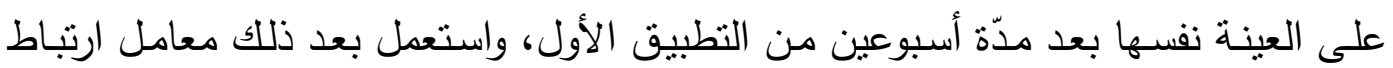

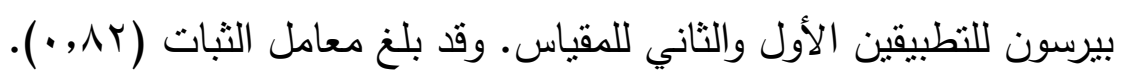
وبهذا اكتمل مقياس اتجاهات طلبة الجامعة نحو الانتقام بصورته النهائية المكونة من

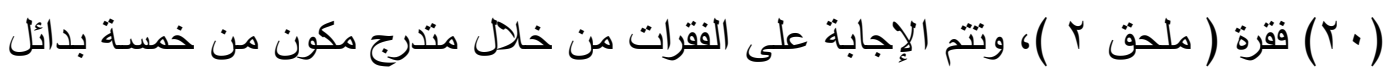
للإجابة. تحمل البدائل الخمسة درجات تتراوح من (ا الى ه). إذ إن الفقرات الإيجابية تكون

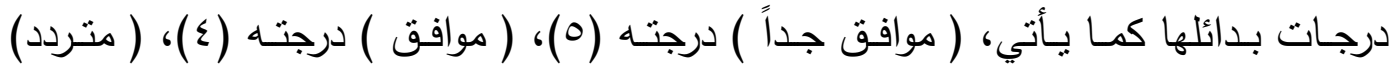

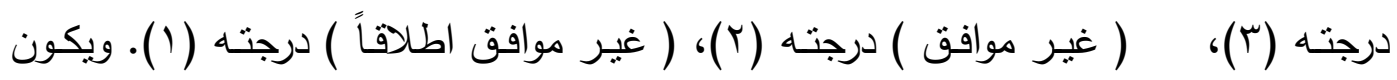
اعطاء الدرجات بالعكس بالنسبة للفقرات السلبية، إذ تكون الدرجات معكوسة بالنسبة لبدائل

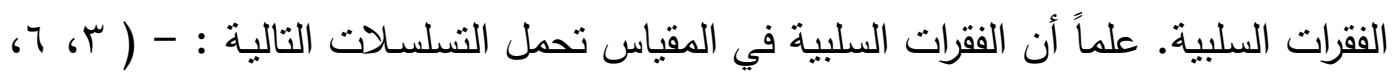

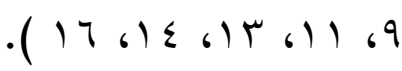

رابعاً: الوسائل الإحصائية:

استعملت في البحث الحالي الوسائل الإحصائية الاتية:

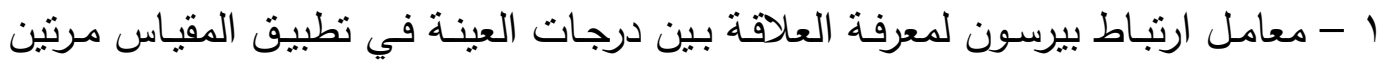
لمعرفة ثبات المقياس. r - الاختبار التائي لعينة واحدة لقياس اتجاهات طلبة الجامعة نحو الانتقام.

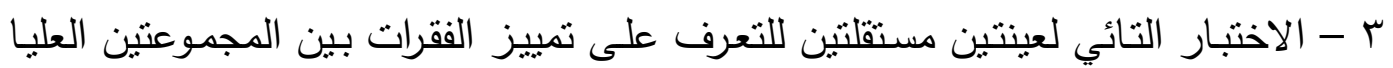

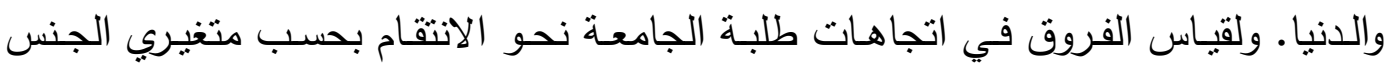

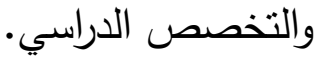

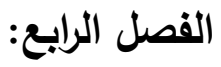

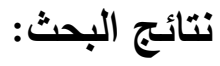
سيقوم الباحث بعرض نتائج البحث طبقاً لأهدافه. وكذلك سيقوم الباحث بمناقثـة هذه

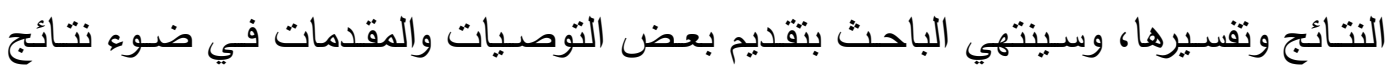
البحث.

الههف الاول: بناء مقياس لقياس اتجاهات طلبة الجامعة نحو الانتقام.

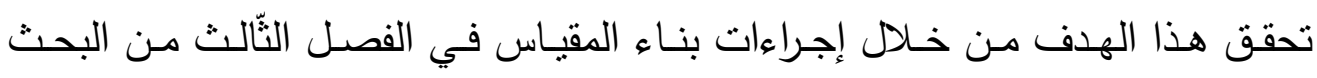

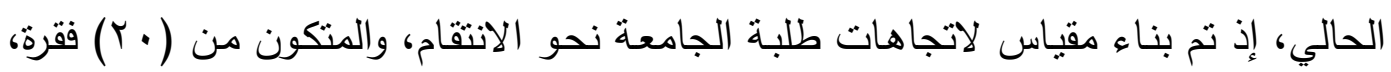
ملحق (r). 
الههف الثاني: قياس اتجاهات طلبة الجامعة نحو الانتقام.

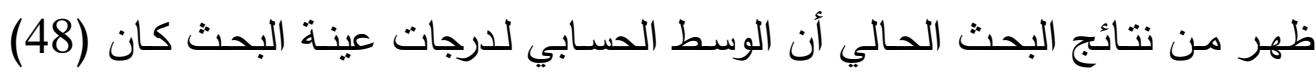

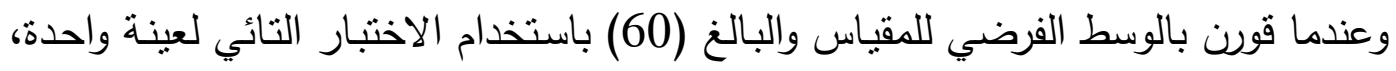

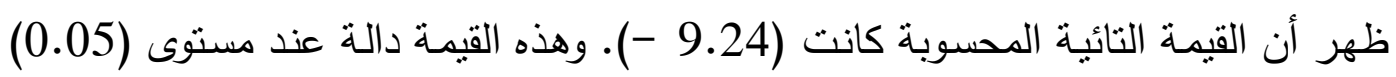
عند مقارنتها بالقيمة التائية الجدولية البالغة (1.96) مما يشير الى أن الطلبة لايهم اتجاهات سلبية نحو الانتقام. والجدول (r) يوضح ذلك. بلك.

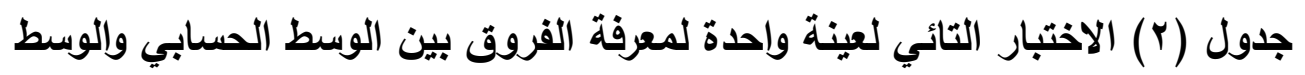

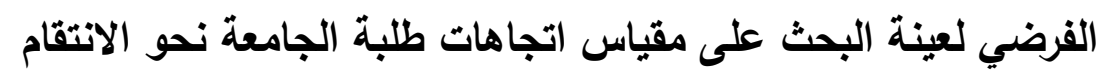

\begin{tabular}{|c|c|c|c|c|c|c|}
\hline مستوى الدلالة & القيمة التائية & القيمة التائية & الانحراف & الفرضط الفرضي & الوسابي & عدد افراد \\
\hline 0.0 & 1.96 & -9.24 & 12.0 & 60 & 48 & 100 \\
\hline
\end{tabular}

تظهر هذه النتيجة أن طلبة الجامعة لديهم اتجاهات سلبية نحو الانتقام، وهذه النتيجة

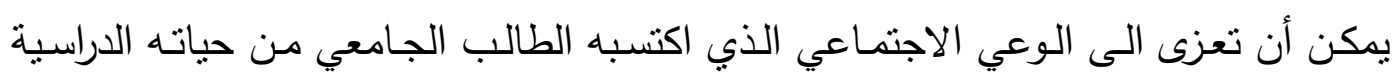

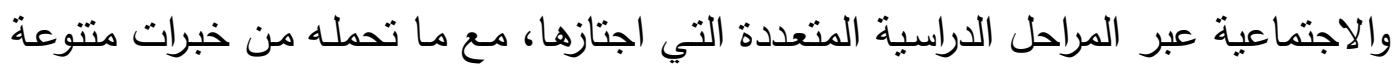

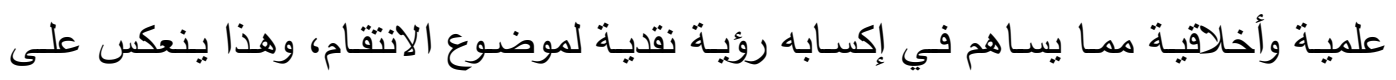

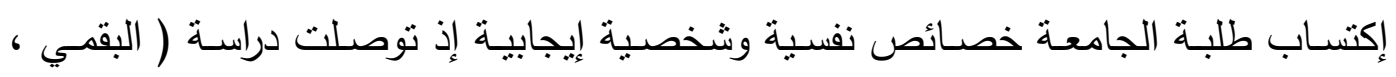

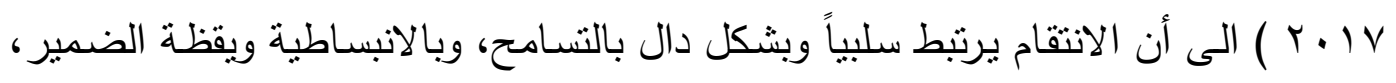

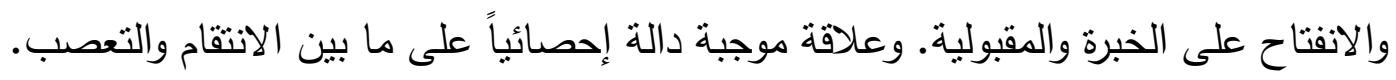

(Baqami, 2017)

الهلف الثالث: التعرف على الفروق في اتجاهات طلبة الجامعة نحو الانتقام على وفق

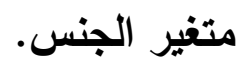
ظهر مـن نتائج البحـث أن الوسط الحسـابي لعينـة الذكور كـان (49.8) وبـانحراف

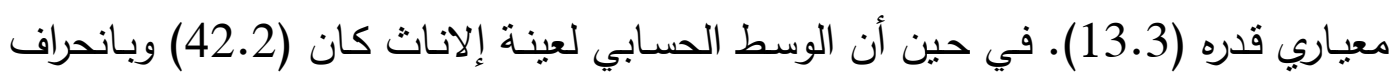
معياري قدره (11.9). وباستخدام الإختبار التائي لعينتين مستقلتين ظهر أن القيطية القيمة التائية

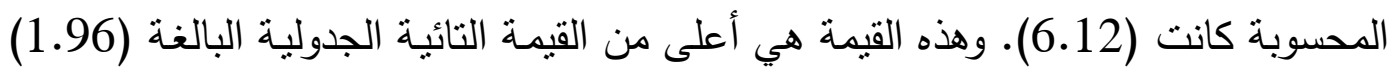

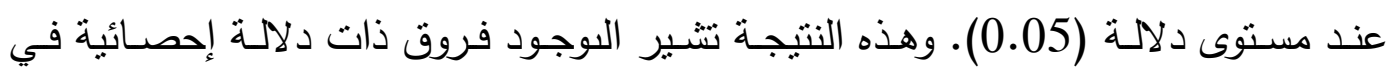

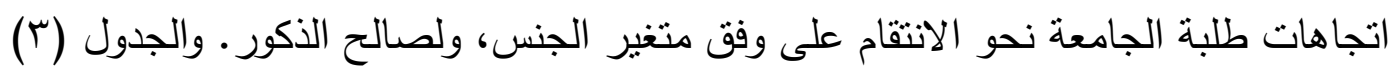
يوضح ذلك. 
جدول (r)الاختبار التائي لعينتي الأكور والاناث لمعرفة الفروق في اتجاهات طلبة الجامعة نحو الانتقام على وفق متغير الجنس

\begin{tabular}{|c|c|c|c|c|c|c|c|}
\hline مستوى & القيمة التائية & القيمة التائية & الانحراف & الصسابي & العدد & العينة & ت \\
\hline \multirow{2}{*}{0.05} & \multirow{2}{*}{1.96} & \multirow{2}{*}{6.12} & 13.3 & 49.8 & 50 & ذكور & 1 \\
\hline & & & 11.9 & 42.2 & 50 & اناث & 2 \\
\hline
\end{tabular}

تثير هذه النتيجة الى أن طلبة الجامعة من الذكور لديهم اتجاهات نحو الانتقام، أكثر

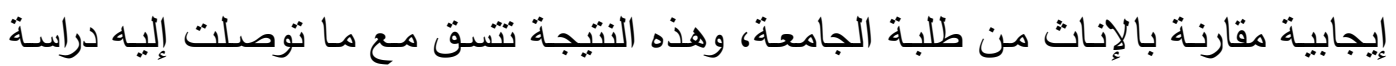

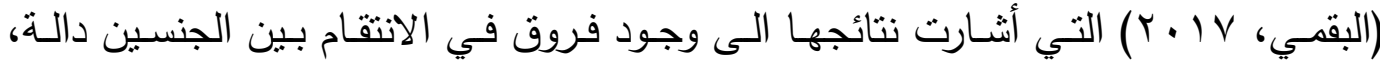

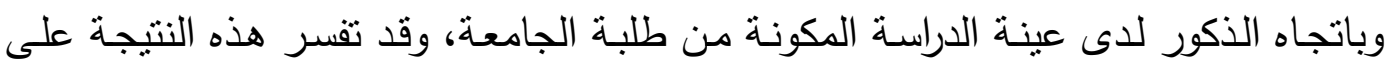

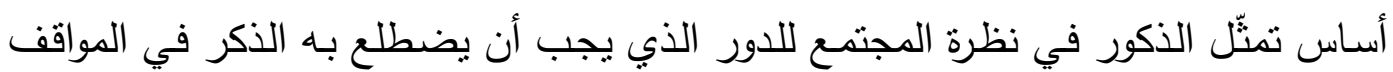

$$
\text { التي تتطوي على إساءة أو اعتداء. }
$$

الهُف الرابع: التعرف على الفروق في اتجاهات طلبة الجامعة نحو الانتقام على وفق اعقى متغير التخصص الاراسي.

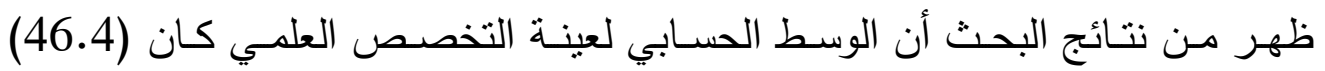
وبانحراف معياري قدره (12.1) في حين أن الوسط الحسابي لعينة التخصص الإنساني كان

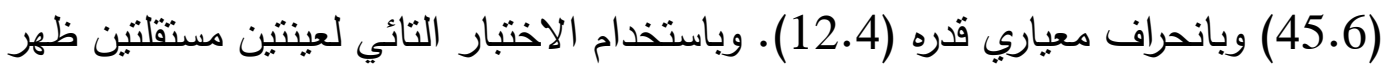

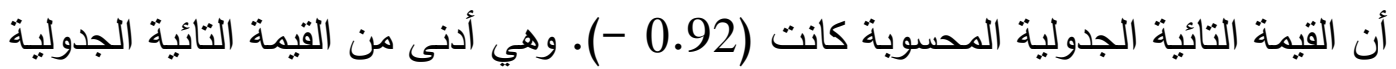
(1.96) عند مستوى دلالة (0.05). وتتير هذه النتيجة الى عدم وجود فروق ذات دلالة إحصائية في اتجاهات طلبة الجامعة نحو الانتقام على وفق للتخصص الدراسي. والجدول (ع) يوضح ذلك.

جدول ( ) الاختبار التائي لعينتي التخصص العلمي والانساني لمعرفة الفروق في اتجاهات طلبة الجامعة نحو الانتقام على وفق متغير بالتخصص الاراسي

\begin{tabular}{|c|c|c|c|c|c|c|c|}
\hline مستوى & القيمة التائية & القيمة التائية & الانحراف & الصسابي & العدد & العينة & ご \\
\hline \multirow{2}{*}{0.05} & \multirow{2}{*}{1.96} & \multirow{2}{*}{-0.92} & 12.1 & 46.4 & 50 & 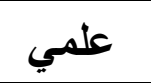 & \\
\hline & & & 12.4 & 45.6 & 50 & انساني & 2 \\
\hline
\end{tabular}

تشير هذه النتيجة الى أن طلبة الجامعة من ذوبي التخصص العلمي لا يختلفون في اتجاهاتهم نحو الانتقام عن طلبة الجامعة من ذوي التخصص الإنساني، وقد يعزى ذلك الى لى أن الانتقام استجابة للإِسـاءة الواقعـة على الفرد الغايـة منها إدامـة الثـعور بـالأمن والسـلام 
الأجتماعي فضـلاً عن تحقيقه أهداف منها استعادة التوازن بين القوى الاجتماعية وحمايـة معتقدات الفرد وادامة المشاعر الإيجابية وصورة الذات، (Al-Baqmi, 2017, 192)، لذا فإن تأثير التخصص الدراسي لا يظهر في اتجاهات طلبة الجامعة نحو الانتقام. التوصيات: في ضوء نتائج البحث الحالي، خرج الباحث بالتوصيات التالية:

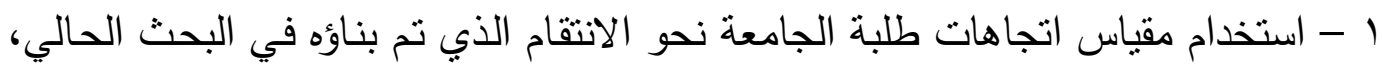
في بحوث مستقبلية يتم إجراؤها على طلبة الجامعة، كما يمكن الإفادة منه من خلال تقنينه وتطبيقه على عينات أخرى مختلفة.

r - إبراز الاتجاهات السلبية لطلبة الجامعة نحو الانتقام بوصفها مظهراً اجتماعياً ونفسياً

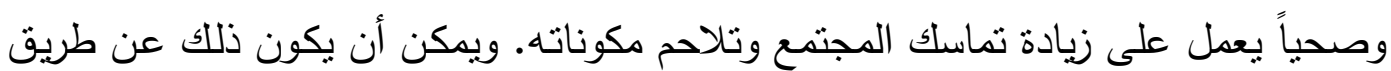
الندوات والمحاضرات ووسائل الإعلام المختلفة.

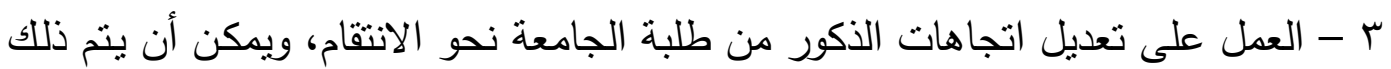

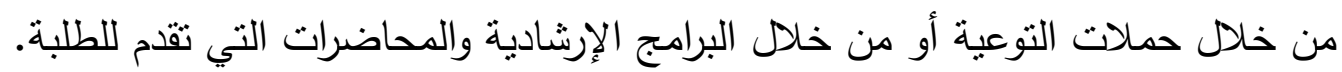

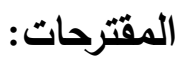
1 - إجـراء دراسـة تسـتهدف التعرف على العلاقـة بـين الاتجاهـات وقطاعـات أخرى مـن المجتمع نحو الانتقام ومتغيراته (سمات الثخصية، الاكتئاب).

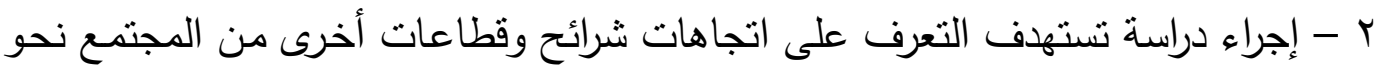
الانتقام، منل ضحايا الجرائم الجنائية وضحايا العنف والإرهاب.

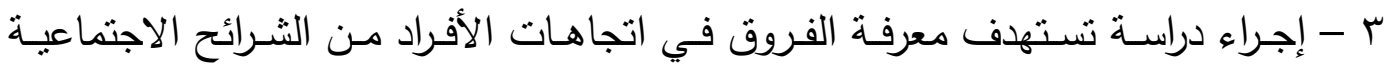
المختلفة نحو الانتقام على وفق المتغيرات الديموغرافية (مستوى التعليم، المهنة، المستوى التهاء (الاقتصادي).

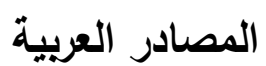

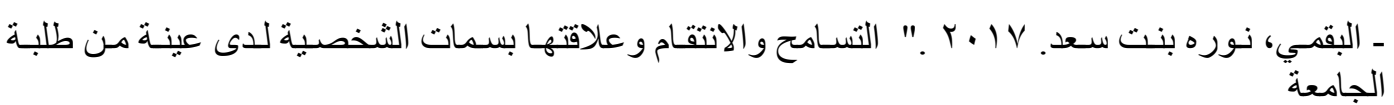
IUG Journal of Education and Psychology Sciences. VOL 25, No 3. Pp 190 - 207.

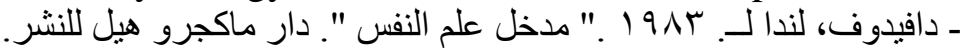

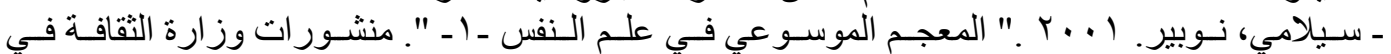

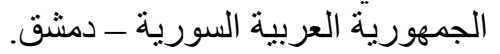
ـ محمد، محمد جاسم. ع . . ب ." الدذخل الى علم النفس العام ". دار الثقافة للنشر و التوزيع. الاردن.

\section{Arabic References}

- Al-Biqamiu, Nura bnt Saed, 2017. "Tolerance and Revenge and its Relationship to the Personality Traits of a Sample of University Students."IUG Journal of Education and Psychology Sciences". VOL 25, No 3. Pp 190 - 207.

- Davidoff, Lind. L, 1983, "Introduction to Psychology". McGraw-Hill Publishing Co.

- Muhammad, Muhammad Jassim, 2004. "Introduction to General Psychology."House of Culture for Publishing and Distribution". Jordan. 
- SILLAMY, NORBERT, 2001,"Dictionnaire usual de Psychologie -1-". Publications of the Ministry of Culture in the Syrian Arab Republic - Damascus.

\section{English References}

- Aquino. K, Robert J. B, Thomas M. TM 2006, "Getting Even or Moving on? Power, Procedural Justice, and Types of Offense as Predictors of Revenge, Forgiveness, Reconciliation, and Avoidance in Organizations" Journal of Applied Psychology, 2006, VOL. 91. NO. 3,653 - 668.

- Aquino. K, Robert J.B, Thomas M.T, 2001. "How Employees Respond to Personal Offense: The Effects of Blame Attribution. Victim Status, and Offender Status on Revenge and Reconciliation in the Workplace". Journal of Applied Psychology, 2001, VOL. 86, NO. $52-59$.

- BREHM. SHARONS, Saul M. KASSIN, STEVEN FEIN, 2002, "Social Psychology Fifth Edition" Houghton Mifflin Company.

- Foster. Charles R, 1986, "PSYCHOLOGY FOR LFE TODAY" AMERICAN SCHOOL.

- Grobbink Leonie H, Jan J. L. Derksen, Hjalmar J. C. van Marle, 2014, "Revenge: An Analysis of Its Psychological Underpinnings" International Journal of offender Therapy and Comparative Criminology. $1-16$.

- McCullough, Michael, Robert Kurzban, and Benjamin A. Taba K. 2013. "Cognitive systems for revenge and forgiveness" Behavioral and Brain sciences 36.01 (2013): 1 - 15.

- Orth, Ulrich, 2004, "Dose Perpetrator Punishment Satisfy Victims feelings of Revenge?" AGGRESSIVE BEHAVIOR, VOL 30, PP 62 - 70.

\section{ملحق ( )}

الاستبيان الاستطلاعي

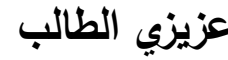

عزيزتي الطالبة

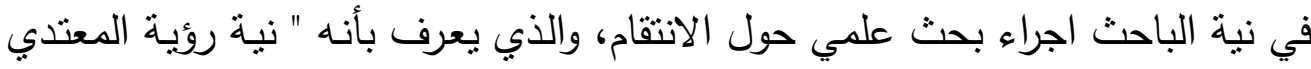

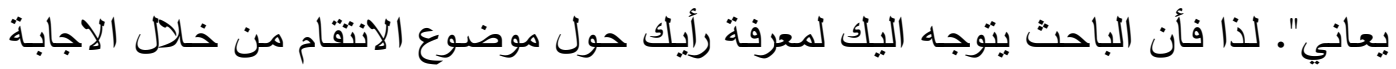

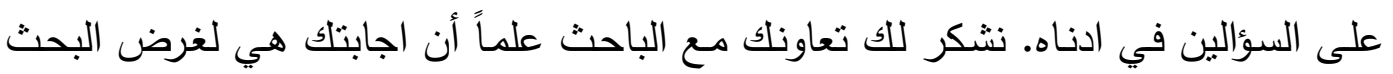
العلمي فقط ولا داعي لذكر الاسم · ..مع وافر التقدير.

السؤال الاول: هل تعتقد أن هناك جوانب ايجابية في الانتقام، اذكرها ؟

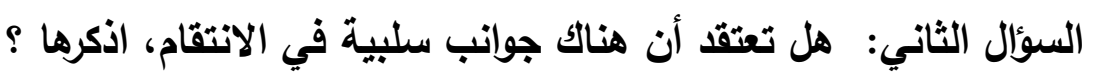

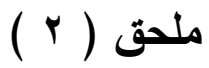

مقياس اتجاهات طلبة الجامعة نحو الانتقام بصورته النهائية

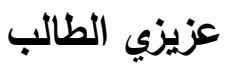
عزيزتي الطالبة

بين يـيك عبارات تتتـاول مواضيع يمكن أن يتفق أو يختلف حولها الافراد. نرجو التفضل بالاطلاع على كل واحده من العبارات، ثم الاجابة عنها من خلاد وضع علامهة 
( V ) تحت البديل الذي يعبر عن رأيك من البدائل التي هي امام العبارات. ان اجابتك سوف تستخدم لأغراض البحث العلمي فقط ولا داعي لذكر الاسم.

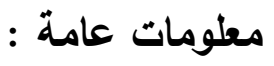
( ) انثى (1)
ذكر ( ع ( )
الجنس : الجن
( ) (نساني (1)
علمي ( ) علر )

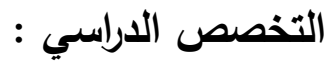

\begin{tabular}{|c|c|c|c|c|c|c|}
\hline غير مو افق & 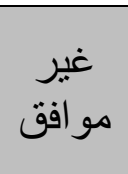 & متردد & مو افق & 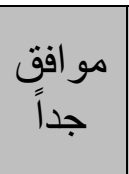 & الفقرات & ت \\
\hline & & & & & العدالة. أن الانتقــام يســاهم فـي تحقــق & 1 \\
\hline & & & & & بسيؤون بلي. & $r$ \\
\hline & & & & & لشعر اكثر بذنبه. ألتسـامح مـع المســيء يجعلـه & $r$ \\
\hline & & & & & هو سلوك مبرر. ألتقام من الثخص المسيء & $\varepsilon$ \\
\hline & & & & & 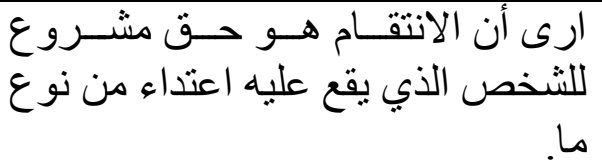 & 0 \\
\hline & & & & & أني افضل المسامحة على الانتقام. & 7 \\
\hline & & & & & 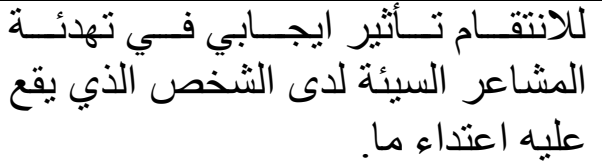 & V \\
\hline & & & & & 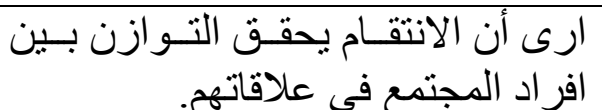 & $\wedge$ \\
\hline & & & & & 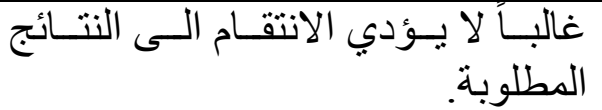 & 9 \\
\hline & & & & & بطريقة افضل الانتقام يجعل الضحية يشعر & 1. \\
\hline & & & & & 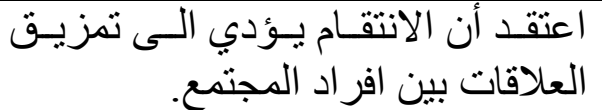 & 11 \\
\hline & & & & & 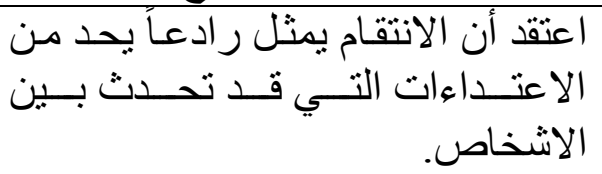 & IT \\
\hline & & & & & بالخجل. أن الانتقام يسبب للمنتقم شـعورا & $1 \pi$ \\
\hline & & & & & غير صحيحة. أنقام ينبع من مشاعر سلبية & $1 \varepsilon$ \\
\hline
\end{tabular}




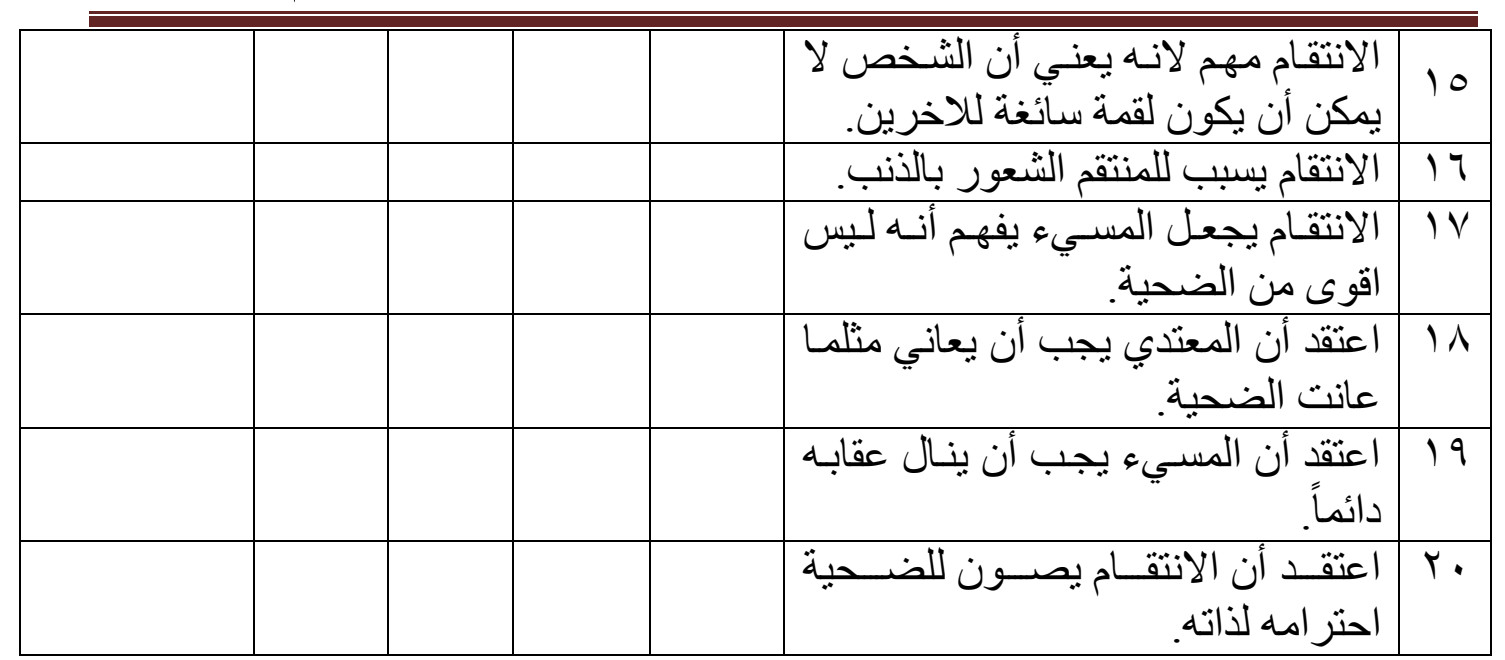

Measuring university students attitudes toward revenge

Dr.. Haider Fadiel Hassan

University of Baghdad / Center for Educational and Psychological

Research

Ph.D in General Psychology

Haider971@perc.uobaghdad.edu.iq

\section{Summary:}

Revenge is an issue that occurs between individuals, caused by the difficulty of tolerating in some individuals with the abuses they encounter in all their stripes. Retaliation: It is the intention to see the aggressor suffer. This research aims to build a measure of university students 'attitudes toward revenge and measure these trends, and to identify the differences in university students' attitudes toward revenge on the gender variable and the variable of academic specialization. The research sample consisted of (100) male and female students from the human and scientific specializations. The researcher built a measure of university students' attitudes toward revenge, which consists of (20) paragraphs, and was applied to the research sample. The results of the research showed that university students have negative attitudes towards revenge, and that there are statistically significant differences in the attitudes of university students towards revenge according to the gender variable and in favor of males, and the results also showed that there are no statistically significant differences in the attitudes of university students towards revenge according to the academic specialization, In the light of its results, the research reached a set of recommendations and proposals.

\section{Keywords: Attitudes. University students. Revenge.}

